\begin{tabular}{|c|c|}
\hline 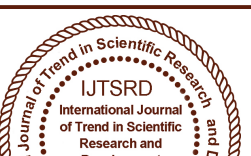 & $\begin{array}{l}\text { International Journal of Trend in Scientific Research and Development (IJTSRD) } \\
\text { International Open Access Journal | www.ijtsrd.com }\end{array}$ \\
\hline 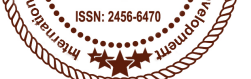 & No: 2456 - 6470 | Volume - 3 | Issue - 1 | Nov - Dec 2018 \\
\hline
\end{tabular}

\title{
Correlation Analysis of Characteristics of Farmers with Their Extent of Adoption of Eco-Friendly Agricultural Practices
}

\author{
V. Kalirajan ${ }^{1}$, K. Kanagasabapathi ${ }^{2}$ \\ ${ }^{1}$ Assistant Professor, ${ }^{2}$ Professor and Head \\ Department of Agricultural Extension, Faculty of Agriculture, Annamalai University, Tamil Nadu, India
}

\section{ABSTRACT}

The study was conducted in Tirunelveli District of Tamil Nadu state in South India. Tirunelveli district is predominantly an agricultural district with more than 70 per cent of the population directly or indirectly associated with agriculture. Tirunelveli district is having all the four different types of cropping systems, considered for the study, viz., wetland, garden land, and dry land systems as well as high elevation cropping system in considerable proportion as compared to other districts of the state. The data were collected by interviewing the respondents personally with the help of Pre-tested and wellstructured interview schedule. The data were processed, coded and tabulated. Statistical analysis like percentage analysis, cumulative frequency distribution and zero-order correlation coefficient were used for analyzing and interpreting the data. The correlation analysis on the characteristics of the farmers revealed that out of fourteen independent variables studied, five variables namely educational status (X2), farming experience (X5), cosmopolites (X8), information sharing behaviour (X11) and attitude towards eco-friendly practices (X14) had shown positive and significant association with the extent of adoption of eco-friendly agricultural practices at 0.01 per cent level probability, while the variables viz., livestock possession (X10) and extension agency contact (X9), mass media exposure (X10), self-confidence (X13) had shown positive and significant association with the adoption of ecofriendly agricultural practices at 0.05 per cent level probability.

\section{INTRODUCTION}

An eco-friendly technology may be defined as the use of knowledge and resources in a systematic way to produce desired output without harming the environment (Reijntjes et al., 1992). The world population of 5.3 billion in 1990 is expected to increase over 10 billion by 2050 . Such a growth in population has created and will create unprecedented pressures on the limited natural resource base to produce additional food, fibre, fuel and raw materials. In the past, these increased requirements were met mainly through technological innovations, institutional and infrastructural development and policy initiatives that promoted growth in agricultural productivity.

With the intention of increasing agricultural production and productivity, farmers have been applying more quantity of chemical fertilizers, plant protection chemicals and thus a lot of damage is done to the soil and environment. At present, the concern for environment is increasing and both scientists and farmers are searching for eco-friendly agricultural technologies. The eco-friendly agricultural practices are recommended by extension workers and practised by farmers.

Agriculture in developing countries like India is promoted mainly by the government organizations; the development and the diffusion of eco-friendly technologies require these government extension agencies. Hence it becomes necessary to study the efforts of the major promoter of agriculture in promoting eco-friendly technologies.

\section{METHODOLOGY}

Tirunelveli district has eleven taluks viz., Tirunelveli, Palayamkottai, Sankarankoil, Tenkasi, Shenkottai, Sivagiri, Nanguneri, Radhapuram, Ambasamudram, Alangulam and V.K. Puthur. In consultation with the statisticians, it was decided to follow three stage 
sampling procedure. Out of 11 taluks, the five taluks which consisted of all types of agro-climatic microzones were selected for this study. The taluks were, Tirunelveli, Sankarankovil, Tenkasi, Shenkottai and Sivagiri. From each taluk, four villages were randomly selected from the list of villages available and thus a total of twenty villages were selected from the five taluks identified for the study. A sample size of 300 was considered adequate for the present study. Out of 20 villages, respondents were selected based on the proportionate random sampling method and thus a total of 300 respondents were identified for the study.

\section{Percentage analysis}

Percentage analysis was done to make simple comparisons wherever necessary.

\section{Cumulative frequency}

The method was suggested by Rao (1983) to categorise the respondents in to low, medium, and high. Based on the score values, the number of respondents belonging to each class was determined. The square root of frequency was calculated. Then the cumulative frequency was multiplied by $1 / 3$ and $2 / 3$ to find out the two boundaries namely $\mathrm{L}_{1} \& \mathrm{~L}_{2}$ respectively. The exact values of these boundries were calculated by using the formula

$$
\mathrm{L}_{1}=\mathrm{K}+\left[\frac{\mathrm{Li}-\mathrm{C}}{\mathrm{f}}\right]_{\mathrm{n}}
$$

Where

$\mathrm{K}=$ Median between lower limit of the class in which $\mathrm{L}_{1}$ occurs and the upper limits of the preview class.

$\mathrm{L}_{1}=$ Boundary values namely $\mathrm{L}_{1} \& \mathrm{~L}_{2}$

Then the three categories were formed as detailed below:

1. Below $L_{1}$ value $=$ low

2. Below $L_{1} \& L_{2}$ values $=$ Medium

3. Above $\mathrm{L}_{2}$ values $=$ High

\section{Zero-order correlation}

Zero-order correlation was worked out of find the degree of relationship of the independent variables with the dependent variable.

\section{RESULTS AND DISCUSSION}

Table-1 Relationship between the characteristics of the farmer with their extent of adoption of ecofriendly agricultural practices

\begin{tabular}{|l|l|l|}
\hline S. No. & \multicolumn{1}{|c|}{ Variables } & Co-efficient $(r)$ \\
\hline$X_{1 .}$ & Age & $0.003^{\mathrm{NS}}$ \\
\hline $\mathrm{X}_{2 .}$ & Educational Status SSN 2456-6470 & $0.199^{* *}$ \\
\hline $\mathrm{X}_{3 .}$ & Occupational Status & $0.024^{\mathrm{NS}}$ \\
\hline $\mathrm{X}_{4 .}$ & Annual Income & $0.004^{\mathrm{NS}}$ \\
\hline $\mathrm{X}_{5 .}$ & Farming Experience & $0.172^{* *}$ \\
\hline $\mathrm{X}_{6 .}$ & Livestock Possession & $0.109^{*}$ \\
\hline $\mathrm{X}_{7 .}$ & Social Participation & $0.107^{\mathrm{NS}}$ \\
\hline $\mathrm{X}_{8}$. & Cosmopoliteness & $0.158^{* *}$ \\
\hline $\mathrm{X}_{9 .}$ & Extension Agency Contact & $0.138^{*}$ \\
\hline $\mathrm{X}_{10 .}$. & Mass Media Exposure & $0.142^{*}$ \\
\hline $\mathrm{X}_{11 .}$. & Information Sharing Behaviour & $0.168^{* *}$ \\
\hline $\mathrm{X}_{12 .}$. & Economic Motivation & $0.113^{\mathrm{NS}}$ \\
\hline $\mathrm{X}_{13 .}$ & Self Confidence & $0.123^{*}$ \\
\hline $\mathrm{X}_{14 .}$ & Attitude towards eco-friendly agricultural practices & $0.135^{* *}$ \\
\hline
\end{tabular}

** Significant at the 0.01 level

* Significant at the 0.05 level

NS- Non significant 
It could be seen from Table-1 that out of fourteen independent variables studied, five variables namely educational status $\left(\mathrm{X}_{2}\right)$, farming experience $\left(\mathrm{X}_{5}\right)$, cosmopolites $\left(\mathrm{X}_{8}\right)$, information sharing behaviour $\left(\mathrm{X}_{11}\right)$ and attitude towards eco-friendly practices $\left(\mathrm{X}_{14}\right)$ had shown positive and significant association with the extent of adoption of eco-friendly agricultural practices at 0.01 per cent level probability, while the variables viz., livestock possession $\left(\mathrm{X}_{10}\right)$ and extension agency contact $\left(\mathrm{X}_{9}\right)$, mass media exposure $\left(\mathrm{X}_{10}\right)$, self-confidence $\left(\mathrm{X}_{13}\right)$ had shown positive and significant association with the adoption of ecofriendly agricultural practices at 0.05 per cent level probability. The remaining variables namely age $\left(\mathrm{X}_{1}\right)$, occupational status $\left(\mathrm{X}_{3}\right)$, annual income $\left(\mathrm{X}_{4}\right)$, social participation $\left(\mathrm{X}_{7}\right)$ and economic motivation $\left(\mathrm{X}_{12}\right)$ did not show any significant relation with the extent of adoption. The significant variables only were considered for discussion

Educational status had shown positive and significant relationship with the extent of adoption of ecofriendly agricultural practices at 0.01 per cent level of probability. Education is a pre- requisite for adoption. Educated people may have better perception ability to grasp things in a better way. Naturally they have understood the significance of eco-friendly agricultural practices. This might have enabled them to gain a high level of adoption. This finding derives support from the findings of Kalaivani (1992) and Smitha (2002).

Farming experience was found to have a positive and significant relationship with the adoption at 0.01 per cent level of probability. It is indicated that the farming experience of the respondents influenced the adoption of eco-friendly agricultural practices. This finding derives support from the findings of Nirmaladevi (1997).

Cosmopolitness had a significant and positive association with the extent of adoption at 0.01 per cent level of probability. This showed that greater the cosmopolites more would be the extent of adoption. Information sharing behaviour showed a positive and significant relationship with extent of adoption at 0.01 per cent level of probability. It may be inferred that most of the respondents had medium level of information sharing behaviour. This would have facilitated them to share and adopt eco-friendly agricultural practices. Attitude towards eco-friendly agricultural practices was found to have positive and significant relationship with the extent of adoption at 0.01 level of probability. It is quiet natural to expect a higher level of adoption from the respondents who have a favourable attitude towards eco-friendly agricultural practices

Livestock possession showed a positive and significant relationship with extent of adoption at 0.05 per cent level of probability. It may be inferred that most of the respondents had medium level of livestock possession. This would have facilitated them to adopt eco-friendly agricultural practices. Extension agency contact was found to have positive and significant relationship with the extent of adoption at 0.05 level of probability. This might be due to frequent contact with extension agency, the respondents might have come to understand the value of eco-friendly agricultural practices and this might have motivated them to adopt the eco-friendly agricultural practices. Mass media exposure showed a positive and significant relationship with the extent of adoption at 0.05 per cent level of probability. This implied that mass media exposure had got direct influence on the extent of adoption of eco-friendly agricultural practices. Self-confidence showed a significant and positive association with the extent of adoption at 0.05 per cent level of probability. This showed that greater the self-confidence more would be the extent of adoption of suggested technologies.

\section{CONCLUSION}

The correlation analysis on the characteristics of the farmers revealed that out of fourteen independent variables studied, five variables namely educational status $\left(\mathrm{X}_{2}\right)$, farming experience $\left(\mathrm{X}_{5}\right)$, cosmopolites $\left(\mathrm{X}_{8}\right)$, information sharing behaviour $\left(\mathrm{X}_{11}\right)$ and attitude towards eco-friendly practices $\left(\mathrm{X}_{14}\right)$ had shown positive and significant association with the extent of adoption of eco-friendly agricultural practices at 0.01 per cent level probability, while the variables viz., livestock possession $\left(\mathrm{X}_{10}\right)$ and extension agency contact $\left(\mathrm{X}_{9}\right)$, mass media exposure $\left(\mathrm{X}_{10}\right)$, selfconfidence $\left(\mathrm{X}_{13}\right)$ had shown positive and significant association with the adoption of eco-friendly agricultural practices at 0.05 per cent level probability. Hence, the experts involved in technology dissemination may be properly trained with the use and importance of indigenous practices in order to change their attitude towards indigenous agricultural practices. 


\section{REFERENCES}

1. Kalaivani, S. 1992. Techno-Cultural Profile of Garden land Farmers, Unpublished M.Sc.(Ag.) Thesis, Tamil Nadu Agricultural University, Coimbatore.

2. Nirmaladevi, M. 1997. Developing a Strategy for Guava Production. Unpublished M.Sc.(Ag.) Thesis, Agricultural College and Research Institute, Tamil Nadu Agricultural University, Madurai.
3. Rao, V. Raghava. 1993. Statistical Techniques in Agricultural and Biological Research. Oxford and IBH Publishing Co., New Delhi.

4. Reijntjes, C., B. Haverkort. And A. Waters-Bayer. 1992. Farming for the Future-An Introduction to Low-external Input and Sustainable Agriculture. Mac Millan Press Ltd., London.

5. Smitha, S. 2002. Yield Gap and Constraints to Rice Production in Kollam District of Kerala-A Micro Level Analysis. Unpublished M.Sc. (Ag.) Thesis, Faculty of Agriculture, Annamalai University, Annamalai Nagar.

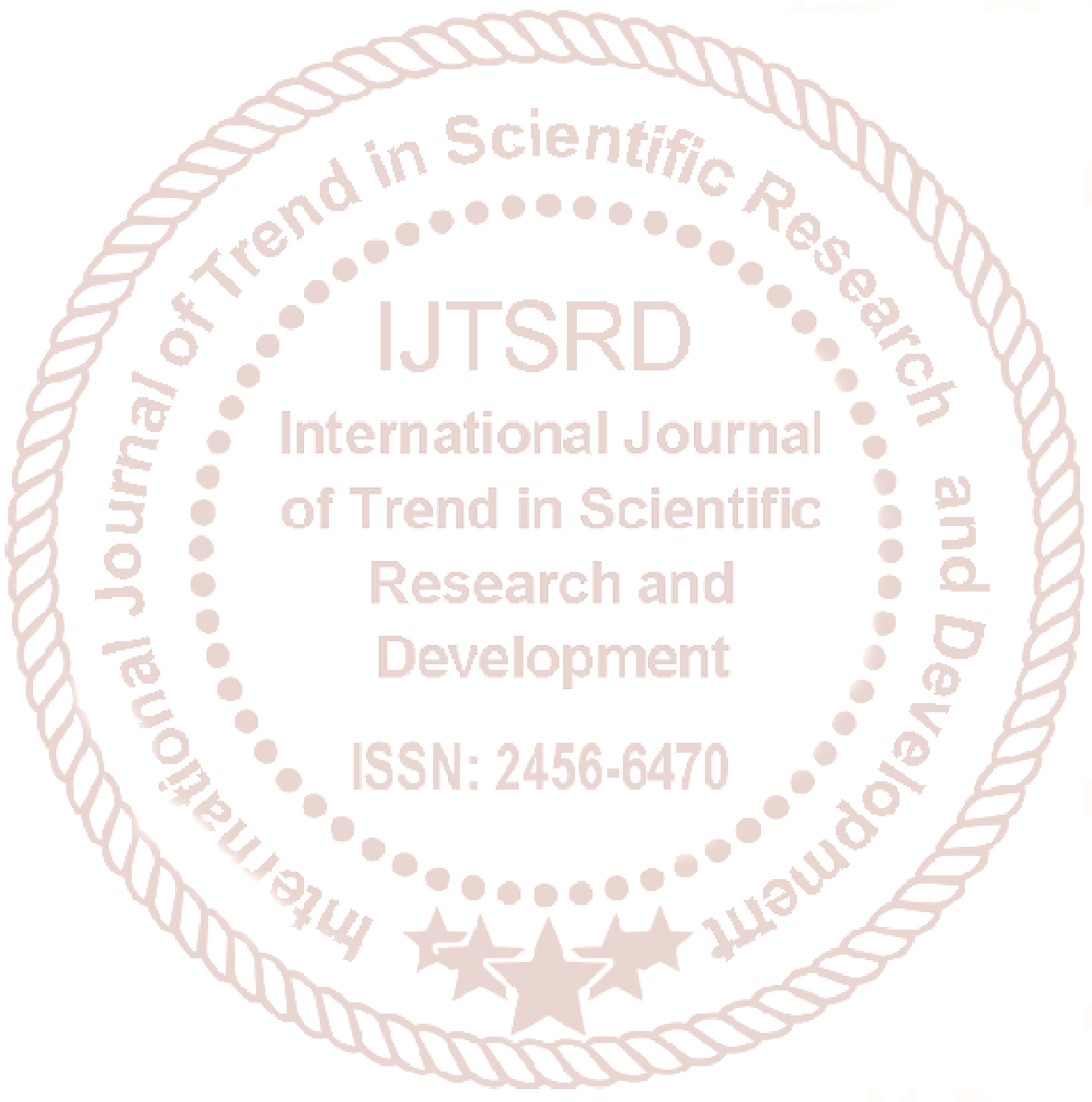

